\title{
Antimicrobial, cytotoxic and antioxidant activity of methanolic extract of Glycyrrhiza glabra
}

\author{
Shapna Sultana ${ }^{{ }^{1}}$. Afroza Haque ${ }^{1}$, Kaiser Hamid ${ }^{1}$, Kaniz Fatima Urmi $^{2}$ and Sumon Roy ${ }^{1}$ \\ Department of Pharmacy, Southeast University, Dhaka, Bangladesh ${ }^{1}$ \\ Department of Pharmacy, Jahangirnagar University, Savar, Bangladesh ${ }^{2}$
}

\begin{abstract}
The present study was undertaken to explore the free radical scavenging, antimicrobial and cytotoxic activity of the methanolic extract of Glycyrrhiza glabra (Fabaceae) using DPPH, disc diffusion and brine shrimp lethality bioassay methods respectively. Different degrees of effect was noticed incase of different methods of study. In antimicrobial screening, G. glabra showed potent antimicrobial activity against almost all the test organisms except Pseudomonas aeruginosa. It exhibited highest sensitivity against Staphylococcus aureus with the zone of inhibition $22 \mathrm{~mm}$. The extract possessed potent cytotoxic activity having $L C_{50}$ value of $0.771 \mu \mathrm{g} / \mathrm{ml}$. On the other hand, the free radical scavenging activity was found moderate having $I C_{50}$ value of $87.152 \mu \mathrm{g} / \mathrm{ml}$.
\end{abstract}

Keywords: Fabaceae, disc diffusion, brine shrimp, free radical scavenging.

\section{INTRODUCTION}

Licorice (Glycyrrhiza glabra L., Pappilionaceae/ Fabaceae) is a well-known medicinal herb that grows in various parts of the world. It is one of the oldest and widely used herbs from the ancient medical history of Ayurveda, both as a medicine and also as a flavoring to disguise the unpleasant flavor of other medications (Biondi et al., 2005).In the traditional system of medicine, the roots and rhizomes of $\mathrm{G}$. glabra (family: Pappilionaceae/ Fabaceae) have been employed clinically for centuries for their antiinflammatory, antiulcer, expectorant, antimicrobial and anxiolytic activities (Wang \& Han, 1993; Asl \& Hosseinzadeh, 2008). Liquorice has been shown to have great antioxidant, free radical scavenging (Haraguchi et al., 1998; Di Mambro \& Fonseca, 2005) and anticonvulsant activities (Nassiri-Asl et al., 2007).

It has been shown to decrease circulating levels of testosterone in men (M.M. Rafi et al 2002, D. Armanini et al 1999, D. Armanini et al 2002). Moreover, it is reported that Licochalcone-A isolated from Glycyrrhiza root demonstrated potent antitumor properties when assayed using $\mathrm{CaP}$, breast, and leukemia cells (DiPaola, et al, 1998)

Isolation of various chemical constituent has been reported previously which include glycyrrhizin, glycyrrhizinic acid (Tang and Eisenbrand, 1992), glabridin, glabrene, glabrol, licoflavonol, glycyrol, licoricone, formononetin, phaseollinisoflavan, hispaglabridin A\&B, 3-hydroxy glabrol, 3-methoxy glabridin (Kinoshita et al., 1976; Mitscher et al., 1978, 1980; Saitoh et al., 1978; Fukai et al., 1996, 2002 $a, b, \quad 2003)$, glabranin isomer, narigenin, lupiwightenone (Biondi et al., 2003, 2005)

The present study was undertaken to evaluate the antioxidant, cytotoxic and antimicrobial activity of Glycyrrhiza glabra so that it could be a guide in the discovery of new molecule with antioxidant, cytotoxic and antimicrobial property.

Plant material: Glycyrrhiza glabra was collected in February 2009 from Dhaka, Bangladesh and authenticated at Bangladesh National Herberium, where a voucher specimen has been deposited.

Extraction and isolation: The air-dried material (60g) was finely pulverized and extracted by percolation with $\mathrm{MeOH}$ for one month at room temperature. The combined extracts were filtered and concentrated under vacuum to obtain a crude extract $(10 \mathrm{~g})$

Antimicrobial activity: The disc diffusion method (Bauer et al, 1966, Rahman et al, 2008) was used to test antimicrobial activity of the extract against thirteen bacteria ( $B$. megaterium, $B$. subtilis, Staphylococcus aureus, Sarcina lutea, Escherichia coli, Pseudomonas aeruginosa, Salmonella paratyphi, S. typhi, Shigella boydii, S. dysenteriae, Vibrio mimicus \& V. parahemolyticus) collected as 
pure cultures from the Institute of Nutrition and Food Science (INFS), University of Dhaka, Bangladesh. Solutions of known concentration $(\mu \mathrm{g} / \mathrm{ml})$ of the test samples were made by dissolving measured amount of the samples in calculated volume of solvents. Dried and sterilized filter paper discs (6 $\mathrm{mm}$ diameter) were then impregnated with known amounts of the test substances using micropipette and the residual solvents were completely evaporated. Discs containing the test materials were placed on to nutrient agar medium uniformly seeded with the test microorganisms. Standard disc of kanamycin (30 $\mu \mathrm{g} / \mathrm{disc}$ ) and blank discs (impregnated with solvents followed by evaporation) were used as positive and negative control, respectively. These plates were then kept at low temperature $\left(4^{\circ} \mathrm{C}\right)$ for 24 hours to allow maximum diffusion of the test materials and kanamycin. The plates were then incubated at $37^{\circ} \mathrm{C}$ for 24 hours to allow maximum growth of the organisms. The test material having antimicrobial activity inhibited the growth of the microorganisms and a clear, distinct zone of inhibition was visualized surrounding the discs. The antimicrobial activity of the test agents was determined by measuring the diameter of zone of inhibition expressed in $\mathrm{mm}$. The experiment was carried out in triplicate and the mean value was taken.

Brian shrimp lethality bioassay: Brine shrimp lethality bioassay (Meyer et al, 1982; Rahman et al, 2008; Hossain et al, 2004) technique was applied for the determination of general toxic property of the extract of Glycyrrhiza glabra Here, in vivo lethality test has been carried out using brine shrimp nauplii eggs (Artemia salina). Eggs were placed in one side of a small tank divided by a net containing $3.8 \% \mathrm{NaCl}$ solution for hatching. In the other side of the tank a light source was placed to attract the nauplii. After 2 days of hatching period the nauplii were ready for the experiment. Four milligrams of the extract was accurately measured and dissolved in DMSO to get a concentration of varying concentrations $100,50,25$, $12.50,6.25,3.125,1.563,0.781,0.39,0.19 \mu \mathrm{g} / \mathrm{ml}$. ten brine shrimp nauplii were then placed in each vial. For the control test of each vial, one vial containing the same volume of DMSO plus water up to $5 \mathrm{ml}$ was used. After 24 hour of incubation, the vials were observed using a magnifying glass and the number of survivors in each vial were counted and noted. From these data, the percentage of mortality of the nauplii was calculated for each concentration and the $\mathrm{LC}_{50}$ value was determined.
Antioxidant Activity: The antioxidant activity (free radical scavenging activity) of the extracts on the stable radical 1,1-diphenyl-2-picrylhydrazyl (DPPH) was determined by the method of Brand-Williams et al., (1995). In the experiment, $2.0 \mathrm{mg}$ of the extract was dissolved in methanol. Solution of varying concentrations such as 500, 250, 125, $62.50,31.25$, $15.62,7.8125,3.91,1.95$ and $0.98 \mu \mathrm{g} / \mathrm{ml}$ were obtained by serial dilution technique. $2 \mathrm{ml}$ of a methanol solution of the extract of each concentration was mixed with $3 \mathrm{ml}$ of a DPPH-methanol solution $(20 \mu \mathrm{g} / \mathrm{ml})$ and was allowed to stand for 20 minutes for the reaction to occur. Then the absorbance was determined at $517 \mathrm{~nm}$ and from these values the corresponding percentage of inhibitions were calculated by using the following equation:

$\%$ inhibition $=\left[1-\left(\mathrm{ABS}_{\text {sample }} / \mathrm{ABS}_{\text {control }}\right)\right] \times 100$

Then \% inhibitions were plotted against respective concentrations used and from the graph $\mathrm{IC}_{50}$ was calculated by using ascorbic acid, a potential antioxidant was used as positive control.

\section{RESULTS AND DISCUSSION}

The methanolic extract of Glycyrrhiza glabra was screened against 12 test bacteria. Most organisms were found to be sensitive to the extract. However, it showed significant antimicrobial activity against Staphylococcus aureus with the zone of inhibition 22 $\mathrm{mm}$. G. glabra exhibited antimicrobial activity against Bacillus subtilis, Escherichia coli but not against Pseudomonas aeruginosa. Evidence showed that due to the presence of glabrene, licoisoflavone B, isolicoflavonol, gancaonin I, it showed significant activity against these microorganisms.

The antimicrobial activity of Glycyrrhiza glabra is well known (Demizu et al., 1988; Yokada et al., 1989; Haraguchi et al., 1998) and glabridin has been reported to possess antibacterial activities against some strains (Mitscher et al., 1980; Fukai et al., 2002b).

In case of brine shrimp lethality bioassay, the lethality of the methanolic extract of Glycyrrhiza glabra was evaluated against $A$. salina. figure-1 shows the results of the brine shrimp lethality testing after 24 hours of exposure to the samples and the positive control, vincristine sulphate (VS). The $\mathrm{LC}_{50}$ were found to be $0.771,0.057 \mu \mathrm{g} / \mathrm{ml}$ for extract and VS, respectively. In comparison with vincristine sulphate, the cytotoxic activity exhibited by the methanolic 
extract of Glycyrrhiza glabra was significant. This clearly indicates the presence of potent bioactive principles in these extractives, which might be very useful as antiproliferative, antitumor, pesticidal and other bioactive agents. (Meyer, et al 1982, Rahman, et al, 2008, Hossain et al., 2004).

In case of antioxidant screening (Figure-2), antioxidant activity with $\mathrm{IC}_{50}$ value of $87.152 \mu \mathrm{g} / \mathrm{ml}$. Standard ascorbic acid had the $\mathrm{IC}_{50}$ value of 22.78 $\mu \mathrm{g} / \mathrm{ml}$. These results denote the presence of antioxidant principles in the extract. Isolation of Isoliquiritigenin (IL), a potent antioxidant agent from Glycyrrhia glabra has been reported in the literature of Chin et al., 2007.

Table-I-Diameter of the zone of inhibition of Glycyrrhiza glabra plant extract

\begin{tabular}{|c|c|c|}
\hline $\begin{array}{l}\text { Name of } \\
\text { Bacteria }\end{array}$ & $\begin{array}{c}\text { Methanolic } \\
\text { extract of } \\
\text { Glycyrrhiza } \\
\text { glabra }\end{array}$ & $\begin{array}{l}\text { Kanamycin } \\
30 \mu g / d i s c\end{array}$ \\
\hline \multicolumn{3}{|l|}{ Gram Positive } \\
\hline $\begin{array}{l}\text { Staphylococcus } \\
\text { aureus }\end{array}$ & 22 & 34 \\
\hline $\begin{array}{l}\text { Bacillus } \\
\text { megaterium }\end{array}$ & 14 & 37 \\
\hline Bacillus subtilis & 16 & 40 \\
\hline Sarcina lutea & 12 & 30 \\
\hline \multicolumn{3}{|l|}{ Gram Negative } \\
\hline $\begin{array}{l}\text { Salmonella } \\
\text { paratyphi }\end{array}$ & 10 & 37 \\
\hline $\begin{array}{l}\text { Salmonella } \\
\text { typhi }\end{array}$ & 10 & 37 \\
\hline Escherichia coli & 16 & 32 \\
\hline $\begin{array}{l}\text { Shigella } \\
\text { dysenteriae }\end{array}$ & 10 & 42 \\
\hline Vibrio minicus & 10 & 37 \\
\hline $\begin{array}{l}\text { Vibrio } \\
\text { parahemolyticus }\end{array}$ & 10 & 30 \\
\hline Shigella boydii & 12 & 37 \\
\hline $\begin{array}{l}\text { Psedomonas } \\
\text { aeruginosa }\end{array}$ & 8 & 30 \\
\hline
\end{tabular}

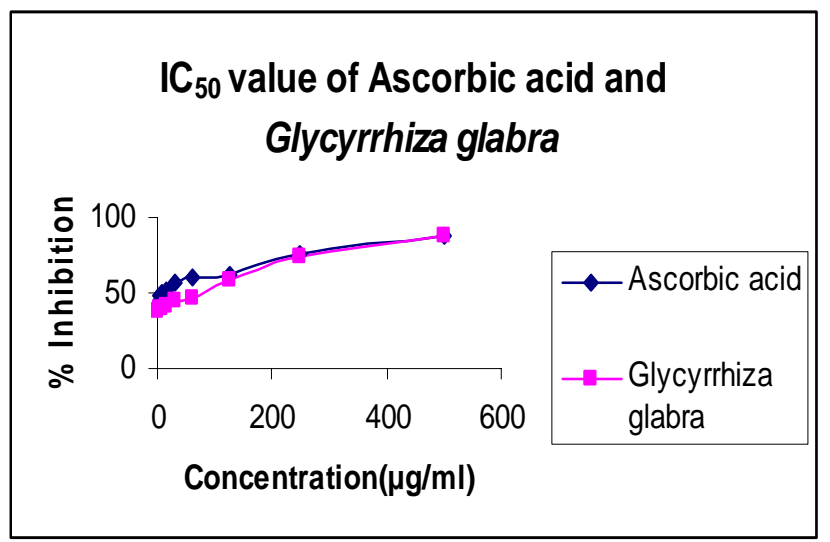

Fig-I: $I_{50}$ value of Ascorbic acid and Glycyrrrhiza glabra

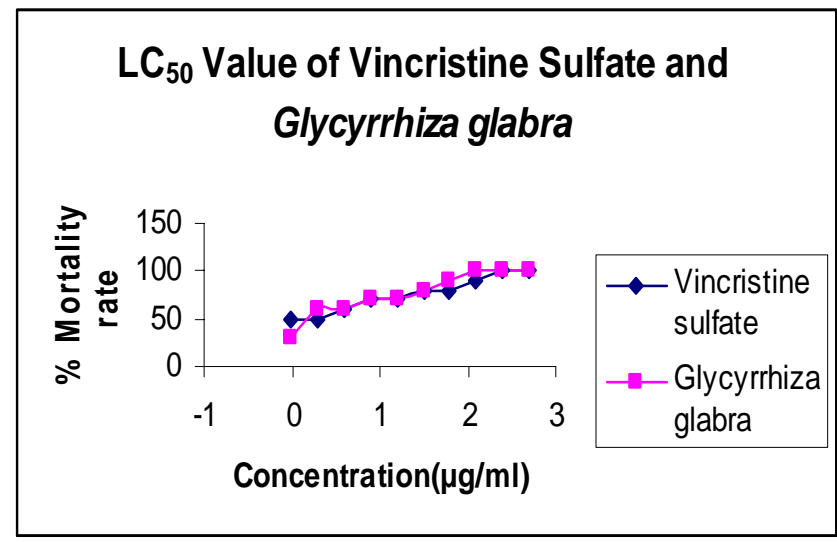

Fig-II LC $_{50}$ value of Vincristine Sulfate and Glycyrrrhiza glabra

\section{REFERENCES}

Asl, M. N. \& Hosseinzadeh, H. (2008) Review of pharmacological effects of Glycyrrhiza sp. and its bioactive compounds. Phytotherapy Research 22, 709-724.

Bauer, A.W., Kirby, W.M.M. Sherries and M. Tuck, 1966. Antibiotic susceptibility testing by a standardized disc diffusion method. J. Am. clin. Pathol. 45, 493-496.

Biondi DM, Rocco C, Ruberto G. 2005. Dihydrostilbene derivatives from Glycyrrhiza glabra leaves. J Nat Prod 68: 1099-1102.

Biondi, D.M., Rocco, C., Ruberto, G., 2005. Dihydrostilbene derivatives from Glycyrrhiza glabra leaves. Journal of Natural Products 68, 1099-1102.

Biondi, D.M., Rocco, C., Ruberto, G., 2003. New dihydrostibene derivatives from the leaves of Glycyrrhiza glabra and evaluation of their antioxidant activity. Journal of Natural Products 66, 477-480.

Brand-Williams, W., M.E. Cuvelier and C. Berset, 1995.Use of a free radical method to evaluate antioxidant 
activity. LWT - Food Science and Technology, 28(1), 25-30.

Chin, Y.W., Jung, H.A., liu, Y., Su, B.N., John, A., Castoro, W.J., Keller, M.A., Douglas, K., 2007. Anti-oxidant constituents of the roots and stolons of licorice (Glycyrrhiza glabra). Journal of Agricultural and Food Chemistry 55, 4691-4696.

D. Armanini, G. Bonanni, M. Palermo, Reduction of serum testosterone in men by licorice, N. Engl. J. Med. 341 (1999) 1158.

D. Armanini, C. Fiore, M.J. Mattarello, J. Bielenberg, M. Palermo, History of the endocrine effects of licorice, Exp. Clin. Endocrinol. Diabetes 110 (2002) 257-261.

Demizu, S., Kajiyama, K., Takahashi, K., Hiraga, Y., Yamamoto, S., Tamura, Y., Okada, K., Kinoshita, T., 1988. Antioxidant and anti-microbial constituents of licorice: isolation and structure elucidation of a newbenzofuran derivative. Chemical and Pharmaceutical Bulletin 36, 3474-3479.

Di Mambro, V. M. \& Fonseca, M. J. (2005) Assays of physical stability and antioxidant activity of a topical formulation added with different plant extract. Journal of Pharmaceutical and Biomedical Analysis 37, 287295.

Fukai, T., Tantai, L., Nomura, T., 1996. Isoprenoid substitute flavonoid from Glycyrrhiza glabra. Phytochemistry 43, 531-532.

Fukai, T., Ali, M., Kaitou, K., Kanda, T., Terada, S., Nomura, T., 2002a. Anti-Helicobacter pylori flavonoids from licorice extract. Life Sciences 71, 1449-1463.

Fukai, T., Marumo, A., Kaitou, K., Kanda, T., Terada, S., Nomura, T., 2002b. Antimicrobial activity of licorice flavonoids against methicillin-resistant Staphylococcus aureus. Fitoterapia 73, 536-539.

Haraguchi, H., Ishikawa, H., Mizutani, K., Tamura, Y. \& Kinoshita,T. (1998) Antioxidative and superoxide scavenging activities of retrochalcones in Glycyrrhiza inflata. Bioorganic\& Medicinal Chemistry 6, 339-347.

Haraguchi, H., Yoshida, N., Ishikawa, H., Tamura, Y., Mizutani, K., Kinoshita, T., 2000. Protection of mitochondrial functions against oxidative stresses by isoflavans from Glycyrrhiza glabra. Journal of Pharmacy and Pharmacology 52, 219-223.

Hossain, M. S., M. A. Hossain, R. Islam , A.H. Alam, Kudrat-e- Zahan, S. Sarkar and M.A.Farooque, 2004. Antimicrobial and cytotoxic activities of 2-aminobenzoic acid and 2-aminophenol and their coordination complexes with Magnesium (Mg- II). Pak. J. Bio. Sci. 7,25-27.

Kinoshita, T., Saitoh, T., Shibata, S., 1976. Flavonols of licorice root. Chemical and Pharmaceutical Bulletin 24, 991-994.

Meyer, B.N., N.R. Ferrigni, J.E. Putnam, J.B. Jacobsen, D.E. Nicholsand and J.L.Mclaughlin,1982. Brine shrimp; a convenient general bioassay for active plant constituents. Planta. Med.45, 31-34.

M.M. Rafi, B.C. Vastano, N. Zhu, C.T. Ho, G. Ghai, R.T. Rosen, M.A. Gallo, R.S. DiPaola, Novel polyphenol molecule isolated from licorice root (Glycyrrhiza glabra) induces apoptosis, G2/M cell cycle arrest, and Bcl-2 phosphorylation in tumor cell lines, J. Agric. Food Chem. 50 (2002) 677-684.

Mitscher, L.A., Park, Y.H., Clark, D., Beal, J.L., 1980. Antimicrobial agents from higher plants, antimicrobial, isoflavanoids and related substances from Glycyrrhiza glabra L. var. typical. Journal of Natural Products 43, 259- 269.

Nassiri-Asl, M., Saroukhani, S. \& Zamansoltani, F. (2007) Anticonvulsant effects of aqueous extract of Glycyrrhiza glabra root in PTZ-induced seizure in mice. International Journal of Pharmacology 3, 432-434.

Rahman, M.S. and M.A.Rashid, 2008. Antimicrobial activity and cytotoxicity of Eclipta prostrata. Oriental Pharm. Exp. Med. 8, 47-52.

R.S. DiPaola, H. Zhang, G.H. Lambert, R. Meeker, E. Licitra, M.M. Rafi, B.T. Zhu, H. Spaulding, S. Goodin, M.B. Toledano, W.N. Hait, M.A. Gallo, Clinical and biologic activity of an estrogenic herbal combination (PC-SPES) in prostate cancer, N. Engl. J. Med. 339 (1998) 785-791.

Saitoh, T., Noguchi, H., Shibata, S., 1978. A new isoflavone and the corresponding isoflavanone of licorice root. Chemical and Pharmaceutical Bulletin 26, 144-147.

Tang,W., Eisenbrand, G., 1992. Chinese Drugs of Plant Origin. Springer-Verlag, Berlin, Germany, pp. 567588.

Wang, G. S. \& Han, Z. W. (1993) The protective action of glycyrrhiza flavonoids against carbon tetrachloride hepatotoxicity in mice. Yao Xue Xue Bao 28, 572-576.

Yokota, T., Nishio, H., Kubota, Y., Mizoguchi, M., 1998. The inhibitory effect of glabridin from liquorice extracts on melanogenesis and inflammation. Pigment Cell Research 11, 355-361. 